\title{
The Influence of the Relative Content of Peat and Mineral Binder on Thermal Insulation Composite Performance Characteristics
}

\author{
Ludmila Voropai $^{1}$, Olga Kuznetsova ${ }^{1}$, Anton Sinitsyn ${ }^{1}$, Olga Yukhtarova ${ }^{1}$, Irina Akhmetova ${ }^{2 *}$, \\ Irina Atamanyuk ${ }^{3}$, Svetlana Ilyashenko 4 \\ ${ }^{1}$ Vologda State University, Lenina Street 15, Vologda, 160000, Russia \\ ${ }^{2}$ Kazan State Power Engineering University, Kazan, Krasnoselskaya Street, 5, 1420066, Russia \\ ${ }^{3}$ Hamburg University of Technology, Hamburg 21073, Germany \\ ${ }^{4}$ Plekhanov Russian University of Economics, Moscow 117997, Russia
}

\begin{abstract}
The relationship between the performance characteristics (e.g., thermal conductivity, specific density, and compressive strength) of a peat heat-insulating composite and its chemical composition has been established. It has also been experimentally proven that high-lying peat and limestone from the Vologda Oblast deposits correspond in chemical composition and structural features to the requirements for producing heat-insulating materials (HIMs). Composite samples with different chemical compositions were obtained under laboratory conditions. To increase the mechanical strength and setting speed when collecting samples, a stage of peat steaming with water vapor and carbon dioxide was provided. HIM testing using modern analytical methods has proven a relationship exists between the content of high-lying peat, quicklime in samples, and their performance characteristics. The optimal chemical composition for obtaining composites was selected. High-lying peat with a moisture content of $30.0 \%$ after steaming and quicklime content of $29.0 \%$ ensured the production of a composite with the following indicators: thermal conductivity of $0.041 \mathrm{~W} / \mathrm{m} \cdot{ }^{\circ} \mathrm{C}$; average density of $259 \mathrm{~kg} / \mathrm{m}^{3}$; compressive strength of $3.02 \mathrm{MPa}$; and toxicity index of less than 0.5 . The established dependence enables simulation of the technological process and obtains materials with the desired properties.
\end{abstract}

Keywords: Heat insulating; HIM; Thermal conductivity

\section{Introduction}

Various composite heat-insulating materials (HIMs) are used in the modern construction industry to create comfortable conditions while reducing energy and material costs during the construction and operation of buildings and structures (Gudkov et al., 2019; Latief et al., 2019; Ujma and Umnyakova, 2019; Pavlov et al., 2020). The distinctive characteristics of these materials are high porosity, low thermal conductivity, and average density to ensure their secondary use as sound-absorbing materials.

Increased material porosity results in a lower resistance to aggressive environmental factors, higher fragility, and water absorption. These features must be considered when developing new types of heat-insulating materials, which always include heat insulators, i.e. the components with porous surfaces (Abdel-Rehim et al., 2006; Baetens, 2013; Han et al., 2015; Abdulkareem et al., 2016; Abu-Jdayil et al., 2019). To increase mechanical strength 
and chemical resistance, binders are added, which can also act as heat insulators, fire retardants, antiseptics, and water repellents (Bekbayeva et al., 2020; Voropai et al., 2020; Yukhtarova, 2020). In construction industry, substances of natural, artificial, and synthetic origin are used as heat insulators (e.g., wood, plant raw materials of fibrous structure, liquid and solid synthetic polymers). Gypsum, limestone, tuffs, Portland cement, slaked lime, quicklime, and dust from construction industries can be used as binders. In recent years, polymers (substances of organic origin) have been used instead of mineral binders (Kopanitsa et al., 2006; 2007; 2010).

When choosing a raw material and its amount, it is necessary to consider not only the ability of materials to form a certain number of pores per unit volume, but also the size of the pores, the degree of their openness or closure, and their shape. It is known that a largepore, concave structure with elongated pores increases the coefficient of thermal conductivity (Ordonez-Miranda and Alvarado-Gil, 2012). Lower thermal conductivity is registered for materials with larger volumes of air trapped in their pores and smaller amounts of solid matter contained in a unit volume of the composite surrounding the pores. Therefore, to obtain an HIM with low thermal conductivity, high mechanical strength, and low specific density, it is necessary to add binders to the composite that will form a single porous structure with HIM after heat treatment and structure formation in air. In our previous work (Yukhtarova, 2020) we developed a new HIM composition based on highlying peat, sawdust, and binding components-gypsum and a mixture of organosilicon polymers and oligomers (K-9, PVB, MSN-7. After heat treatment, an HIM with useful characteristics (thermal conductivity of $0.049 \mathrm{~W} / \mathrm{m} \cdot{ }^{\circ} \mathrm{C}$; compressive strength of $1.59 \mathrm{MPa}$; average density of $242 \mathrm{~kg} / \mathrm{m}^{3}$ ) was obtained. The aim of this work is to develop a new technology for producing insulating composite with reduced energy, material costs, and product costs, while maintaining the relevant requirements for construction materials, simplifying the technology required for their production, and resolving issues of production waste disposal. Quicklime setting processes occur at lower temperatures than those of gypsum setting processes, so our newly developed technology will use high-lying peat and quicklime as raw materials. The carbonization and hydration processes of quicklime after steaming cause a more porous and solid structure to be formed with a lower specific gravity than a gypsum-based composite.

This paper presents the production stages according to the new technology and establishes the impact of chemical composition on HIM performance characteristics. The course of the work obtained the following: (i) properties and chemical composition of natural raw materials (i.e., high-lying peat and quicklime); (ii) samples of heat insulators using the newly developed technology; (iii) testing of obtained samples to determine the optimal composition of the initial mixture, heat treatment conditions, and obtained composite properties.

\section{Materials and Methods}

During the first stage of the study, peat and limestone characteristics were examined to assess the possibility of their use as raw materials during thermal insulation material production. Low-lying and high-lying peats differ in the degree of decomposition and chemical composition, yet both can be used as raw materials during HIM production. Lowlying peat has a high degree of decomposed plant remains and is characterized by a low degree of pore development, high adhesive and enveloping properties, and high humic acid content. Therefore, composites based on low-lying peat have the disadvantage of high thermal conductivity and specific density. By contrast, high-lying peat is characterized by a low degree of decomposed plant residues; their preserved structures serve as a skeleton 
for composite preparation. Such peat allows insulators with developed porous structure, high mechanical strength, and low specific gravity to be obtained.

Peat samples taken from four locations in the Maega deposit (Vologda region, Russia) were tested for type, degree of decomposition, moisture content, ash content, organic matter content, and $\mathrm{pH}$ value of the aqueous extract. Limestone samples were taken at different depths from six locations of the Belo-Rucheysky deposit (Vytegorsky district of the Vologda region). The gravimetric, photoelectric-colorimetric, and titrimetric methods of analysis were used to determine the samples properties. The combustion method was used to analyze the peat for the content of organic and inorganic substances. Samples of high-lying peat were calcined in a SNOL-7.2/11000 muffle furnace (Russia) at temperatures ranging from 250 to $300^{\circ} \mathrm{C}$. The mass of the solid residue was then determined and the ash content was calculated using the expression:

$$
A=\frac{m-m_{1}}{m_{2}} \cdot 100, \%
$$

where $A$ is the ash content percentage, $m$ is the mass of crucible in grams with ash residue, $m_{1}$ is the mass in grams of the empty crucible, and $m_{2}$ is the mass in grams of dry soil.

During the study's second stage, the conditions for obtaining HIM samples were determined. A heat treatment of the heat-insulating mixture was carried out using the muffle furnace. Obtained samples were parallelepipeds with front face dimensions of $150 \times 150 \mathrm{~mm}$; sample thicknesses were in the range of 10-40 mm. Treatment with water vapor and carbon dioxide was carried out in a reactor. The peat was placed on corrugated shelves, and a mixture of water vapor and carbon dioxide was passed through until the moisture content of the samples reached $30 \%$.

With constant stirring, a concentrated emulsion of quicklime was added to the treated peat, which was followed by a three-hour holding in air at room temperature to set the quicklime and form structures. After stabilization in air, the samples were subjected to heat treatment at a temperature range of $100-105^{\circ} \mathrm{C}$ for 30 minutes to complete the structure formation and remove excess unreacted water. The degree of setting and sample hardening was determined using a Vicat apparatus.

The third stage of the study saw obtained composite samples tested and their main characteristics obtained. Thermal conductivity was measured in the range 0.02-1.5 $\mathrm{W} /(\mathrm{m} \cdot \mathrm{K})$; limits of permissible relative error for thermal conductivity were $\pm 5 \%$ with measurement times between 0.5 and 2.5 hours. To improve experimental accuracy, thermal conductivity was also determined using the formula of V.P. Nekrasov:

$$
\lambda=1.16 \sqrt{0.0196+0.22 \cdot d^{2}}-0.16, \mathrm{~W} /(m \cdot K)
$$

where $d$ is the material density with respect to water density $\left(997 \mathrm{~kg} / \mathrm{m}^{3}\right)$.

To measure the ultimate compressive strength, a testing machine was used to determine the load that would destroy the material structure with an error of $1 \%$. The compressive strength was calculated by the following formula:

$$
R_{\mathrm{cs}}=\frac{P}{l \cdot b}, \mathrm{kgf} / \mathrm{cm}^{2}
$$

where $P$ is the breaking force (i.e., the highest load noted in Newtons (kgf) during sample testing at the time of its destruction), $l$ is the sample length in $\mathrm{cm}$, and $b$ is the sample width, in $\mathrm{cm}$. The test results were rounded to the nearest $0.01 \mathrm{MPa}$. The average density of materials was determined gravimetrically, taking sample volume into account. Each experiment was repeated at least three times to eliminate random errors and obtain the true average values. 
An important characteristic of building materials is their toxicity, which was determined using the toxicity analyzer BIO-LAT, with a visualization system and software for the mathematical processing of biotesting expressive and long-term results. The toxicity indicator was determined by ciliate time of death. Table 1 shows the toxicity assessing criteria. In the expressive mode, the survival rate of ciliates Paramecium caudatum and Tetrahymena pyriformis was determined using 4 hours of contact with water extracted from composite samples. In the long-term regime, ciliates were stored in water extracted from composite samples for 30 days, with the reproductive functioning of the protozoa being established using testing.

Table 1 Toxicity assessment criteria

\begin{tabular}{lcc}
\hline \multicolumn{1}{c}{ Toxicity class } & Time of ciliate death & Toxicity index \\
\hline Non-toxic & after $3 \mathrm{~h}$ & $<0.5$ \\
Weakly toxic & before $3 \mathrm{~h}$ & $0.5-0.7$ \\
Toxic & before $10 \mathrm{~min}$ & $0.7-0.9$ \\
Highly toxic & in $3 \mathrm{~min}$ & $>0.9$ \\
\hline
\end{tabular}

The study's fourth stage included a comparison of characteristics for the obtained samples with previous results, and the fifth stage obtained composite properties on the basis of comparisons between five-component and three-component mixtures.

\section{Results and Discussion}

\subsection{Characteristics of Peat and Limestone}

The obtained characteristics of the high-lying peat from the Maega deposit are presented in Table 2 . The results indicate poorly decomposed peat of pine-suffruticous type that contained undecomposed porous remains of plant root system, which would serve as a skeleton when obtaining a composite. The average organic matter content was $88.17 \%$ and the average $\mathrm{pH}$ value of the aqueous extract was 6.12 (slightly acidic medium). The latter must be taken into account when obtaining composite as quicklime setting times increase in acidic environments. The average ash content (residual amount of inorganic substances after combustion) was $11.82 \%$, and the moisture content was $12.89 \%$. The results of calculating the material balance show that this amount of water was not sufficient for the quicklime to completely set.

Table 2 Characteristics of high-lying peat from the Maega deposit

\begin{tabular}{ccccc}
\hline Sample No. & $\begin{array}{c}\text { Moisture, } \\
W, \%\end{array}$ & $\begin{array}{c}\text { Ash content, } \\
\%\end{array}$ & $\begin{array}{c}\text { Organic matter } \\
\text { content, } \%\end{array}$ & $\begin{array}{c}\mathrm{pH} \text { of aqueous } \\
\text { extract }\end{array}$ \\
\hline 1 & 12.82 & 11.78 & 88.22 & 6.1 \\
2 & 12.92 & 11.79 & 88.21 & 6.2 \\
3 & 12.94 & 11.86 & 88.14 & 6.1 \\
4 & 12.88 & 11.87 & 88.13 & 6.1 \\
Average & 12.89 & 11.82 & 88.17 & 6.12 \\
\hline
\end{tabular}

The chemical composition of quicklime was determined after calcination at a temperature of $450-520^{\circ} \mathrm{C}$. On average, the samples consisted of calcium oxides (89.1\%), magnesium (1.3\%), iron (2.2\%), aluminum (1.8\%), silicon (3.2\%), and unidentified impurities (2.4\%). As the high-lying peat of the Maega deposit and the limestone of the BeloRucheysky deposit possessed high calcium and magnesium oxide content, they had binding properties and could be used to obtain HIM. 


\subsection{Examination of Conditions for Obtaining HIM Samples}

The established chemical composition of quicklime was used to determine the required amounts of water vapor and carbon dioxide for setting. The content of unbound peat water was taken into account, which is discussed later. Figure 1 shows the relationship between HIM yield and quicklime content.

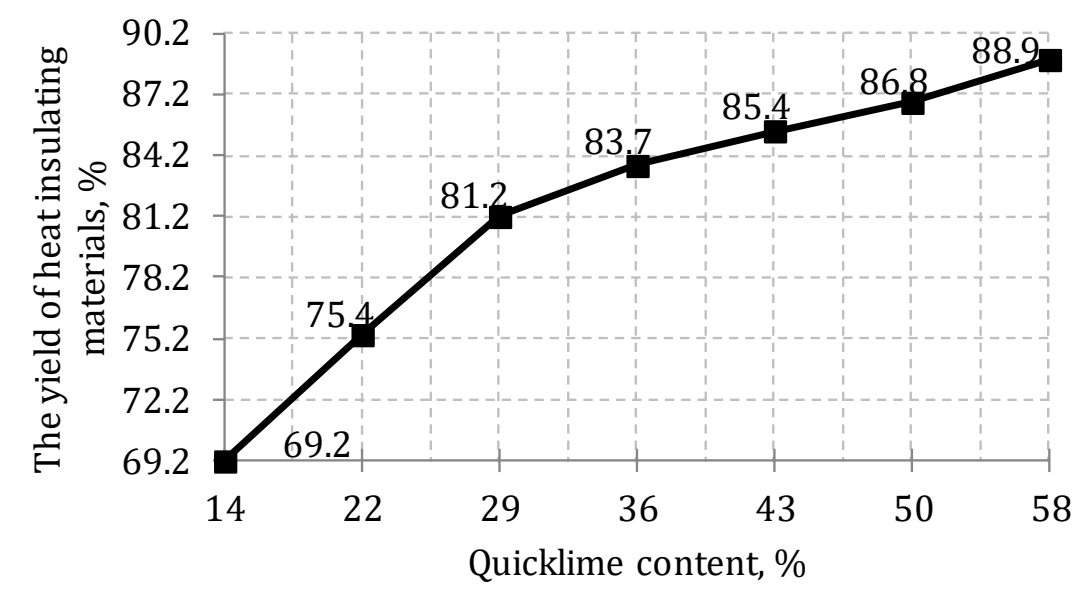

Figure 1 The relationship between HIM yield and quicklime content

It was experimentally established that after treating high-lying peat with water and carbon dioxide before subsequently adding quicklime created a more uniform composite structure after setting. When water was added to the mixture of peat and quicklime without steaming, a disorderly structure was formed with inclusions of unreacted slaked lime that formed cracks during subsequent heat treatment.

The optimal degree of peat impregnation with water and carbon dioxide is $28.0-30.0 \%$ of the mass of peat dry sample. Carbon dioxide, when interacting with quicklime, forms inclusions of solid carbonates, which envelop peat particles. At a lesser degree of impregnation, unreacted areas of quicklime remain in the structure; at higher humidity values (e.g., 35.0, 40.0, and 45.0\%), an increase in thermal conductivity is observed above the permissible values established by the Russian State Standard GOST (GOST 4861-74). This proves the need to impregnate peat with water vapor and carbon dioxide.

The performed examination showed that HIM samples with different chemical compositions were obtained.

\subsection{Examination of the Obtained Composite Samples}

Table 3 presents the main characteristics of the obtained composite samples.

Table 3 Composite sample testing results

\begin{tabular}{lccccccc}
\hline \multirow{2}{*}{ Characteristics } & \multicolumn{7}{c}{ Sample No. } \\
\cline { 2 - 8 } & 1 & 2 & 3 & 4 & 5 & 6 & 7 \\
\hline Average density, $\mathrm{kg} / \mathrm{m}^{3}$ & 231 & 248 & 259 & 273 & 318 & 352 & 401 \\
Thermal conductivity, $\mathrm{W} / \mathrm{m} \cdot{ }^{\circ} \mathrm{C}$ & 0.033 & 0.038 & 0.041 & 0.054 & 0.061 & 0.065 & 0.068 \\
Compressive strength, MPa & 2.44 & 2.70 & 3.02 & 3.10 & 3.30 & 3.32 & 3.36 \\
Toxicity index & 0.5 & 0.5 & 0.5 & 0.5 & 0.5 & 0.5 & 0.5 \\
\hline
\end{tabular}

Figure 2 shows the relationship between the average density and chemical composition of samples. 


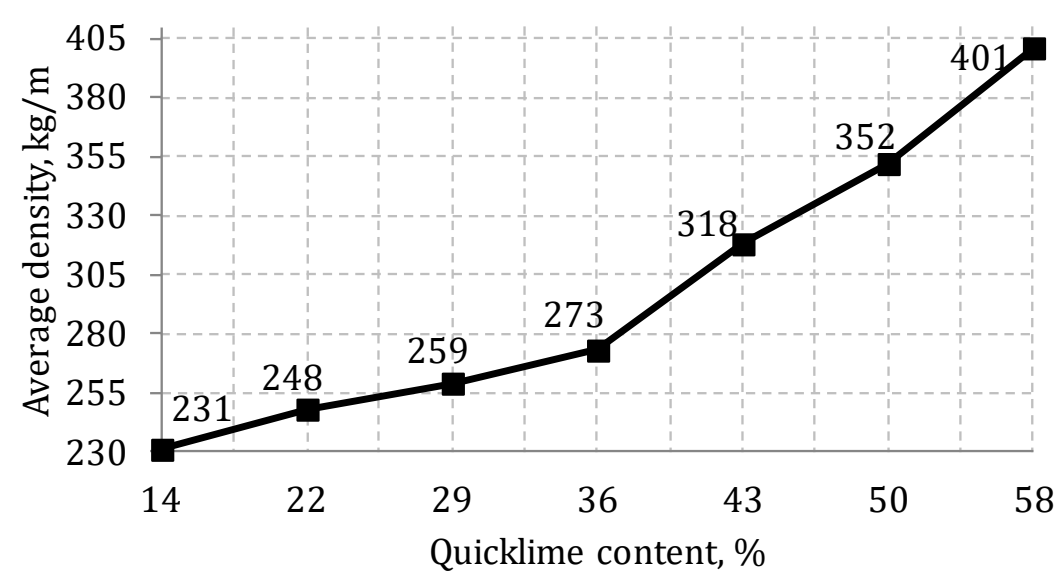

Figure 2 The relationship between the average density and chemical composition of samples

Figure 3 shows the relationship between the thermal conductivity coefficient and sample chemical composition.

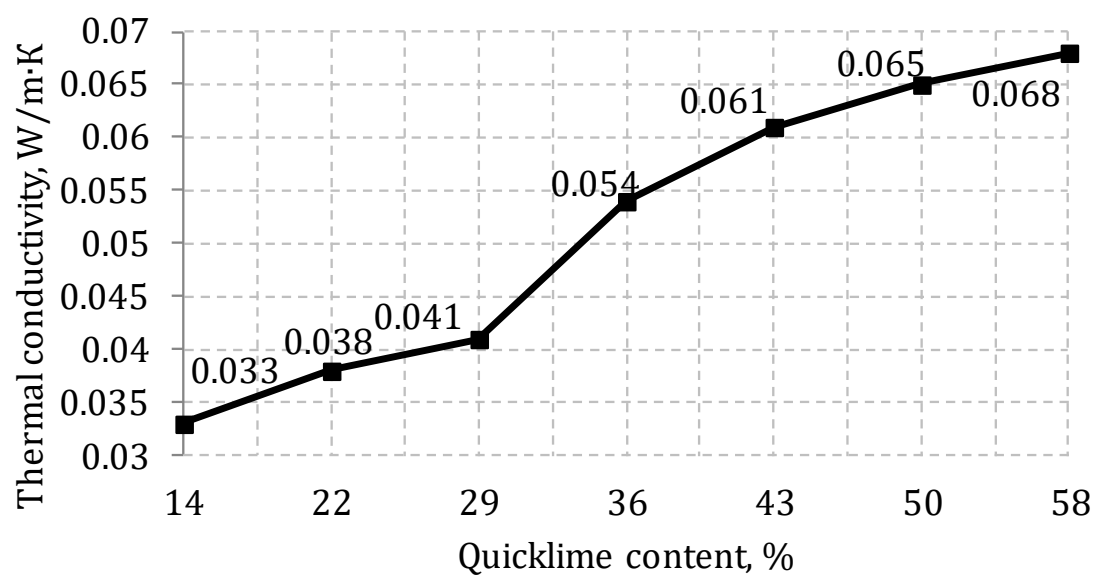

Figure 3 The relationship between the thermal conductivity and chemical composition of samples

Figure 4 shows the relationship between the compressive strength and chemical composition of samples.

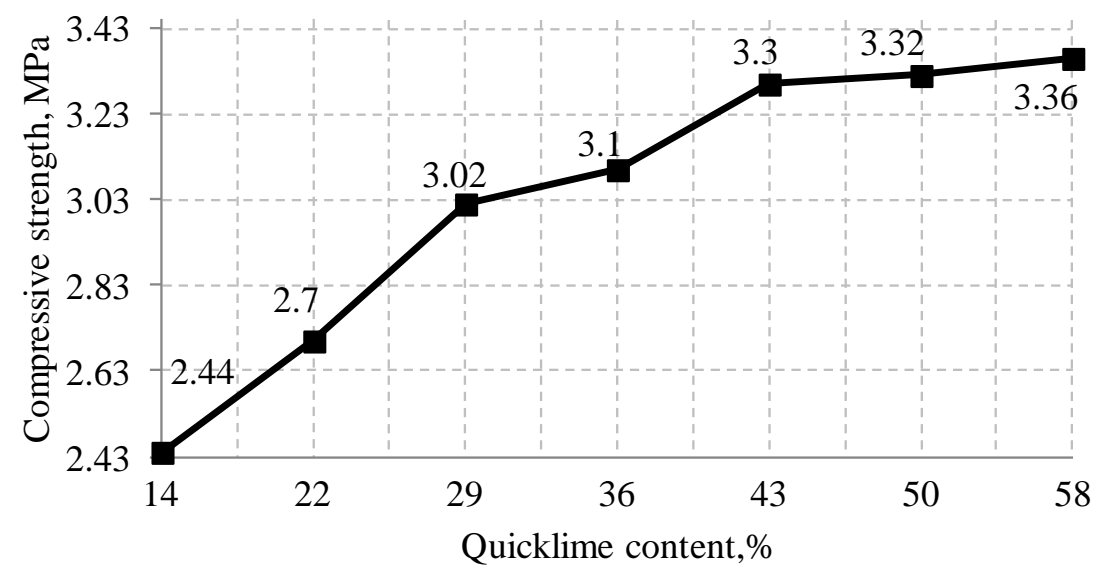

Figure 4 The relationship between the compressive strength and the chemical composition of samples 


\subsection{Comparison of Obtained Sample Properties with Previous Results}

The properties of the obtained samples were compared with previous test samples containing a three-component organic polymer (Yukhtarova, 2020). The relationship between chemical composition and product yield was found.

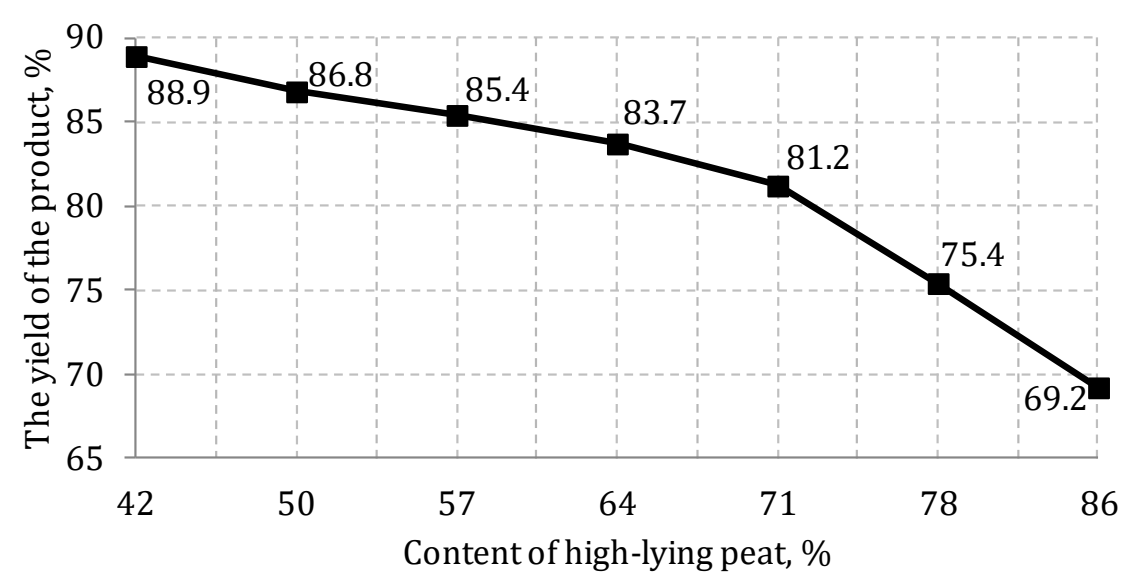

Figure 5 Relationship between product yield and high-lying peat content chemical composition

The research results showed that product yield depends on the peat and quicklime content in the initial mixture. Given a $14.0 \%$ quicklime content with $86.0 \%$ peat and moisture content of $30.0 \%$, the composite yield was minimal (amounting to $69.2 \%$ ). This is explained by excess water being introduced into the system, which does not correspond to the quicklime content, evaporating after 30 minutes of heat treatment at a temperature range of $100-105^{\circ} \mathrm{C}$. Decreasing the content of moist peat in the composite from 86 to $42.0 \%$, and increasing the quicklime content from 14 to $58.0 \%$, increased composite yield to $88.9 \%$ and increased average sample density from 231 to $401 \mathrm{~kg} / \mathrm{m}^{3}$. Samples 1, 2, and 3 have densities ranging from 170 to $260 \mathrm{~kg} / \mathrm{m}^{3}$. Figure 5 illustrates the dependence of product yield on sample chemical composition. These results prove the relationship between chemical composition and composite characteristics. Increasing the peat content and decreasing the quicklime content saw thermal conductivity decrease from 0.068 to $0.033 \mathrm{~W} / \mathrm{m} \cdot{ }^{\circ} \mathrm{C}$, Figure 3 . A sharp increase in thermal conductivity was observed in Samples 4 and 5, which held quicklime content of 36.0 and $43.0 \%$, respectively. Increasing in quicklime content further from 50.0 to $58.0 \%$ (Samples 6 and 7) caused slight thermal conductivity changes. The residual amount of liquid vapors in the pores and the specific density of the samples had a great influence on the thermal conductivity, matching behavior observed by Stapulionienè et al. (2015). The thermal conductivity for Samples 1, 2, and 3 was lower than the conductivity specified by Russian State Standard GOST 4861-74 (GOST 4861-74). Therefore, the obtained samples had high thermal insulation properties and could be used as heat insulators.

The study results also indicated the dependence of mechanical strength on sample chemical composition. The maximum compressive strength was recorded for Sample 7 (3.36 MPa), which contained the highest quicklime concentration (58\%). However, samples of this composition also had thermal conductivity exceeding permissible GOST values. It was found that decreasing peat content while increasing quicklime content increased compressive strength from 2.44 to $3.36 \mathrm{MPa}$. For Samples 1 and 2, strength indicators were below the permissible GOST 4861-74 (GOST 4861-74) values (3-4 kg/m³).

Indicators showed all samples were non-toxic; toxicity index less than 0.5 . We draw special attention to Sample 3, which contained $29.0 \%$ quicklime and $71.0 \%$ moist peat, 
showing composite yield of $81.2 \%$, a thermal conductivity coefficient of $0.041 \mathrm{~W} / \mathrm{m} \cdot{ }^{\circ} \mathrm{C}$, an average sample density of $259 \mathrm{~kg} / \mathrm{m}^{3}$, and a compressive strength of $3.02 \mathrm{MPa}$. These statistics meets the GOST requirements for HIMs (GOST 4861-74). These characteristics are also comparable with the characteristics of thermal insulation material made of low-moor peat with binder, frame component (wooden aggregate), and additive (Vasiljeva and Korjakins, 2017).

Our previous studies (Sinitsyn et al., 2020; Yukhtarova, 2020) have shown that introducing a three-component polymer into a composite mixture consisting of high-lying peat, sawdust and gypsum increases mechanical strength while decreasing average density and thermal conductivity. However, further testing showed that the polymer engulfs the gypsum, peat, and sawdust particles, causing a gradual decrease in porosity during the formation of a solid structure.

\subsection{Comparison of Five-component and Three-component Mixture Compositions}

The three-component composite consisted of high-lying peat steamed with water and carbon dioxide (bringing it to a moisture content of 30\%), quicklime, and water; the fivecomponent blend included polymer, gypsum, sawdust, high-lying peat, and water. It was found that adding three-component polymer to an equivalent amount of peat increased average sample density (231 and $227 \mathrm{~kg} / \mathrm{m}^{3}$ ), decreased compressive strength $(2.44-1.29$ $\mathrm{MPa})$, and increased thermal conductivity $\left(0.033-0.044 \mathrm{~W} / \mathrm{m} \cdot{ }^{\circ} \mathrm{C}\right)$.

In the presence of a polymer, the formation of a solid composite structure occurs at a temperature of $200^{\circ} \mathrm{C}$ over 1.5 hours. Lowering the temperature to $110^{\circ} \mathrm{C}$ will slow the composite structure formation to 3 hours. The three-component composite, which does not contain polymer, was heated for 30 minutes at $105^{\circ} \mathrm{C}$ to evaporate free moisture. The formation of a more porous structure was observed, causing a decreased thermal conductivity coefficient and average density while maintaining high compressive strength. Reducing the heating time simplifies the HIM production technology while offering the advantages of reduced energy and material costs. An increase in the mineral content of gypsum or quicklime contributed to an increase in average density, thermal conductivity, and compressive strength. For example, doubling the gypsum content increased average density by 1.07, compressive strength by 1.14, and thermal conductivity by 1.12 .

In the absence of a polymer and with an increase in quicklime content by a factor of 2 , the change in thermal conductivity and average density was approximately equal to that of a five-component composite. Thus, the replacement of gypsum with quicklime while excluding sawdust and polymer from the composition caused a decrease in the average sample density and the thermal conductivity coefficient while maintaining strength characteristics with a simpler technological scheme for obtaining samples. This is the advantage of the three-component composite.

\section{Conclusions}

The properties of naturally available materials (high-lying peat taken from the Maega deposit of the Vologda region and quicklime obtained from the limestone of the BeloRucheysky deposit in the Vytegorsky district of the Vologda region) were studied. The obtained results prove their value in producing thermal insulation materials.

A new type of HIM based on high-lying peat and quicklime was obtained. In contrast to typical technologies, the formation of a solid structure occurred by processing wet peat samples with a mixture of water vapor and carbon dioxide, then carbonizing quicklime. Testing results proved that replacing gypsum with quicklime while excluding sawdust and a three-component polymer from the composite helped simplify the technology for 
obtaining HIM while improving HIM characteristics. The relationship between the operational properties of the obtained composite samples and their chemical composition was established. Based on this relationship, it is possible to simulate the technology of obtaining composites. The optimal chemical composition for obtaining composites was selected. The content of high-lying peat with a moisture content of $30.0 \%$ (after treatment with water and carbon dioxide) and $29.0 \%$ quicklime provided a composite with the following indicators: thermal conductivity coefficient is $0.041 \mathrm{~W} / \mathrm{m} \cdot{ }^{\circ} \mathrm{C}$; average density is $259 \mathrm{~kg} / \mathrm{m}^{3}$; compressive strength is $3.02 \mathrm{MPa}$; toxicity index is less than 0.5 .

\section{References}

Abdel-Rehim, Z.S., Saad, M.M., El-Shakankery, M., Hanafy, I., 2006. Textile Fabrics as Thermal Insulators. Autex Research Journal, Volume 6(3), pp. 148-161

Abdulkareem, S., Ogunmodede, S., Aweda, J.O., Abdulrahim, A.T., Ajiboye, T.K., Ahmed, I.I., Adebisi, J.A., 2016. Investigation of Thermal Insulation Properties of Biomass Composites. International Journal of Technology, Volume 7(6), pp. 989-999

Abu-Jdayil, B., Mourad, A.H., Hittini, W., Hassan, M., Hameedi, S., 2019. Traditional, State-OfThe-Art and Renewable Thermal Building Insulation Materials: An Overview. Construction and Building Materials, Volume 214, pp. 709-735

Bekbayeva, L., Negim, E.-S., Gulzhakhan, Y., Ganjian, E., 2020. Utilization of Poly(Polyvinyl Alcohol-g-2-Ethylhexyl Acrylate) as Admixture for Mortar. International Journal of Technology, Volume 11(2), pp. 259-268

Baetens, R., 2013. High performance Thermal Insulation Materials for Buildings. In: Nanotechnology in Eco-Efficient Construction: Materials, Processes and Applications. PachecoTorgal, F., Diamanti, M.V., Nazari, A.; Granqvist, C.G. (Editors). Woodhead Publ LTD. Cambridge, Sawston, United Kingdom doi:10.1533/9780857098832.2.188

GOST 4861-74., 1981. Peat Thermal-insulating Plates. Moscow: Izdatelstvo Standartov

Gudkov, P., Kagan, P., Pilipenko, A., Zhukova, E.Y., Zinovieva, E.A., Ushakov, N.A., 2019. Usage of Thermal Isolation Systems for Low-Rise Buildings as a Component of Information Models. E3S Web of Conferences, Volume 97. doi:10.1051/e3sconf/20199701039

Han, Y., Zhang, X., Wu, X., Lu, C., 2015. Flame Retardant, Heat Insulating Cellulose Aerogels from Waste Cotton Fabrics by in Situ Formation of Magnesium Hydroxide Nanoparticles in Cellulose Gel Nanostructures. ACS Sustainable Chemistry and Engineering, Volume 3(8), pp. 1853-1859

Kopanitsa, N.O., Kudyakov, A.I., Kalashnikova, M.A,. 2006. Patent 2273620 RF, MPK S 04 B 38/06. Peat-Wood Composition for the Manufacture of Heat-Insulating Building Materials. Applicant and patentee GOUVPO "TGASU". - No. 2004108271/03; decl. 03/22/2004; publ. 10.04.2006, bul. No. 10

Kopanitsa, N.O., Kudyakov, A.I., Kalashnikova, M.A., 2007. Patent 2307813 RF, MPK (51) S 04B 38/00. Peat-Wood Composition for the Manufacture of Structural and Thermal Insulation Materials. Applicant and patentee GOUVPO “TGASU”. - No. 2005130585/03, decl. 03.10.2005; publ. 10.10.2007, bul. No. 28

Kopanitsa, N.O., Kudyakov, A.I., Kalashnikova, M.A., 2010. Patent 2393128 RF, MPK S 04 B 26/00. Thermal Insulation Composition for the Production of Peat-Based Building Materials. Applicant and patentee GOUVPO “TSASU”. - No. 2008101233/03; decl. 09.01.2008; publ. 06/27/2010, bul. No. 18

Latief, Y., Berawi, M.A., Koesalamwardi, A.B., Sagita, L., Herzanita, A., 2019. Cost Optimum Design of a Tropical Near Zero Energy House (nZEH). International Journal of Technology, Volume 10(2), pp. 376-385

Ordonez-Miranda, J., Alvarado-Gil, J., 2012. Effect of the Pore Shape on the Thermal 
Conductivity of Porous Media. Journal of Materials Science, Volume 47, pp. 6733-6740 Pavlov, M., Karpov, D., Akhmetova, I., Monarkin, N., 2020. Assessment of Energy Efficiency of Application Heat-Insulating Paint for the Needs of District Heat Supply Systems. E3S Web of Conferences, Volume 178. doi:10.1051/e3sconf/202017801004

Sinitsyn, A., Voropay, L., Salikhova, R., Yukhtarova, O., 2020. Relationship between Operational Properties of Peat Heat-insulating Materials and the Content of Mineral Binders in Them. E3S Web Conferences. Volume 178. doi: 10.1051/e3sconf/202017801047

Stapulionienè, R., Vaitkus, S., Kremensas, A., 2015. Thermal Conductivity Investigation of Composite from Hemp and Peat Fibres. Environmental Engineering and Management Journal, Volume 14(9), pp. 2213-2220

Ujma, A., Umnyakova, N., 2019. Thermal Efficiency of the Building Envelope with the Air Layer and Reflective Coatings. E3S Web of Conferences, Volume 100. doi:10.1051/e3sconf/201910000082

Vasiljjeva, T., Korjakins, A., 2017. The Development of Peat and Wood-based Thermal Insulation Material Production Technology. Construction Science, Volume 20(1), pp. 60-67

Voropai, L., Duryagina, Y.A., Sinitsyn, A.A., Yukhtarova, O.S., 2020. Development of a New Method for Producing Heat-Insulating Materials based on High-Lying Peat and Fluorine-Containing Polymers. In: Materials of the All-Russian Scientific and Practical Conference: "Modern Trends in the Development of Chemical Technology, Industrial Ecology and Technosphere Safety", St. Petersburg, Russia, pp. 310-313. V.A. Basova (Editor). Higher School of Technology and Power Engineering of Saint-Petersburg State University of Industrial Technologies and Design

Yukhtarova, O.S., 2020. Dependence of the Physical and Mechanical Properties of Composite Thermal Insulation Materials on the Structure of Peat and its Content in the Composite. In: Materials of the XVI International Scientific and Practical Conference "Strategic Issues of World Science”, Vol. IV: Problems of Scientific Thought, Poland, p. 17. Moscow, Internauka 